\title{
Sterile insect technique and Wolbachia symbiosis as potential tools for the control of the invasive species Drosophila suzukii
}

\author{
Katerina Nikolouli ${ }^{1,5} \cdot$ Hervé Colinet $^{2} \cdot$ David Renault $^{2,3} \cdot$ Thomas Enriquez $^{2} \cdot$ Laurence Mouton $^{4} \cdot$ Patricia Gibert $^{4}$. \\ Fabiana Sassu ${ }^{1,5} \cdot$ Carlos Cáceres $^{5} \cdot$ Christian Stauffer $^{1} \cdot$ Rui Pereira $^{5} \cdot$ Kostas Bourtzis $^{5}$
}

Received: 24 February 2017 / Revised: 30 November 2017 / Accepted: 2 December 2017 / Published online: 13 December 2017

(c) The Author(s) 2017. This article is an open access publication

\begin{abstract}
Drosophila suzukii, a vinegar fly originated from Southeast Asia, has recently invaded western countries, and it has been recognized as an important threat of a wide variety of several commercial soft fruits. This review summarizes the current information about the biology and dispersal of $D$. suzukii and discusses the current status and prospects of control methods for the management of this pest. We highlight current knowledge and ongoing research on innovative environmental-friendly control methods with emphasis on the sterile insect technique (SIT) and the incompatible insect technique (IIT). SIT has been successfully used for the containment, suppression or even eradication of populations of insect pests. IIT has been proposed as a stand-alone tool or in conjunction with SIT for insect pest control. The principles of SIT and IIT are reviewed, and the potential value of each approach in the management of $D$. suzukii is analyzed. We thoroughly address the challenges of SIT and IIT, and we propose the use of SIT as a component of an area-wide integrated pest management approach to suppress D. suzukii populations. As a contingency plan, we suggest a promising alternative avenue through the combination of these two techniques, SIT/IIT, which has been developed and is currently being tested in open-field trials against Aedes mosquito populations. All the potential limiting factors that may render these methods ineffective, as well as the requirements that need to be fulfilled before their application, are discussed.
\end{abstract}

Keywords Biological control $\cdot$ Greenhouse $\cdot$ Incompatible insect technique $\cdot$ Integrated pest management $\cdot$ Spotted wing Drosophila

\section{Key message}

Communicated by N. Desneux.

Kostas Bourtzis

K.Bourtzis@iaea.org

1 Department of Forest and Soil Sciences, Boku, University of Natural Resources and Life Sciences, Vienna, Austria

2 UMR ECOBIO CNRS 6553, Université de Rennes, 1, 263 AVE du Général Leclerc, 35042 Rennes Cedex, France

3 Institut Universitaire de France, 1 rue Descartes, 75231 Paris, Cedex 05, France

4 Laboratoire de Biométrie et Biologie Evolutive, Univ. Lyon, Université Claude Bernard Lyon 1, CNRS, 69100 Villeurbanne, France

5 Insect Pest Control Section, Joint FAO/IAEA Division of Nuclear Techniques in Food and Agriculture, Wagramerstrasse 5, PO Box 100, 1400 Vienna, Austria
- Drosophila suzukii has invaded the Americas and Europe, and it has become a significant global pest of a wide variety of soft fruit crops.

- We review current knowledge on management practices used so far to control D. suzukii and discuss innovative biological control methods.

- The SIT can be used as part of an area-wide integrated pest management (AW-IPM) strategy to control $D$. suzukii in greenhouses and other confined locations.

- A combined SIT/IIT strategy should be considered as a contingency plan. 


\section{Introduction}

Invasive species have been recognized as important threats of biodiversity and cause substantial yield and revenue losses in agricultural systems (Bolda et al. 2010; Goodhue et al. 2011; Pimentel et al. 2000, 2005). The spotted wing Drosophila (SWD), Drosophila suzukii, was originally described by Matsumura in Japan in 1931. Recently, D. suzukii has invaded North and South America (Bolda et al. 2010; Deprá et al. 2014) and Europe (Calabria et al. 2012; Cini et al. 2012). The most probable source for the western North American populations seems to be southeast China and Hawaii, while European populations are probably originated from northeast China, with evidence of limited gene flow from eastern USA as well (Fraimout et al. 2017). Members of the Drosophila genus are not generally considered as pests since their larvae are primarily developed on damaged or rotting fruits. Nevertheless, D. suzukii infests healthy ripening fruits while still on the plant. Drosophila suzukii larvae consume the fruit pulp inside the fruits rendering them unmarketable and decreasing the processed fruit quality (Walsh et al. 2011). Moreover, the wounds created on the infested fruits during oviposition provide access to secondary fungal or bacterial infections leading to additional fruit tissue collapse (Asplen et al. 2015; Cini et al. 2012; Goodhue et al. 2011; Ioriatti et al. 2015; EPPO 2010; Walsh et al. 2011). Drosophila suzukii has a wide range of hosts including both cultivated fruits and wild plants (Asplen et al. 2015;
Diepenbrock and Burrack 2017; Grant and Sial 2016; Poyet et al. 2014, 2015). This species has thus become a significant worldwide pest (Fig. 1) of a large variety of commercial fruit crops. Drosophila suzukii is differentiated from other drosophilids based on two key morphological traits: (a) females have an enlarged serrated ovipositor which enables them to infest and cause physical damage to the ripening fruit and (b) males are characterized by a dark spot on the leading edge of the wings.

Significant damage has been observed in several commercial soft fruits, such as blackberries, blueberries, cherries, raspberries, strawberries, tomatoes, grapes, cherries, figs, kiwis (Ioriatti et al. 2015; Lee et al. 2015; Poyet et al. 2015; EPPO 2010; Rota-Stabelli et al. 2013; Tochen et al. 2014). Recent studies have shown that specific host fruits favor the oviposition and development of larvae, while temperature plays a crucial role on D. suzukii development, survival and fecundity (Ioriatti et al. 2015; Lee et al. 2011a, b; Tochen et al. 2014).

First records of $D$. suzukii in North America date back to 2008 (Hauser and Gaimari 2009; Walsh et al. 2011). In Europe, this fly was first recorded in Spain in autumn 2008 (Calabria et al. 2012) and in North Italy in 2009 (Grassi et al. 2011). By the end of 2010, D. suzukii had colonized the Western and Eastern USA, Canada, and most of the Mediterranean regions (Rota-Stabelli et al. 2013). Latest records report the presence of this pest in additional countries such as Austria, UK, Belgium, Germany, Hungary, Romania Turkey, Ukraine, Brazil, Chile, Argentina and Uruguay (Asplen et al. 2015; Calabria et al. 2012; Cini et al. 2012; Chireceanu et al.

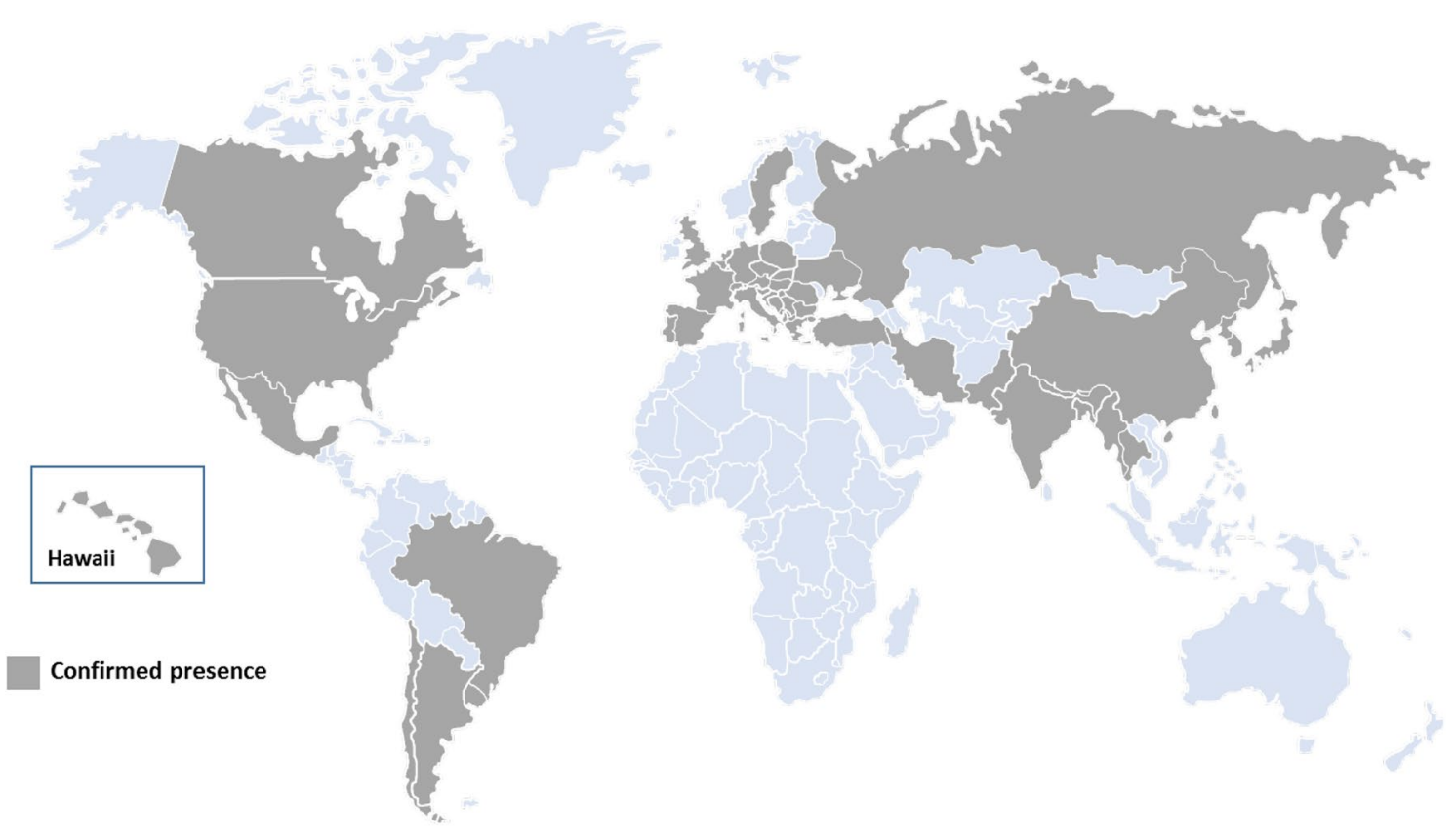

Fig. 1 Worldwide confirmed distribution of D. suzukii (as of August 2017) 
2015; Deprá et al. 2014; Lavrinienko et al. 2017; Lengyel et al. 2015; Lue et al. 2017; Orhan et al. 2016; Servicio Agrícola y Ganadero (SAG) 2017; Vilela and Mori 2014). The expansion of $D$. suzukii in North and South America and in Europe has been very fast and widespread (Adrion et al. 2014; Lasa and Tadeo 2015). Adults of $D$. suzukii demonstrate a high dispersal potential, which is mainly attributed to the increasing global trade and the pest's invasion behavior (Calabria et al. 2012; Lengyel et al. 2015; Rota-Stabelli et al. 2013). From an ecological standpoint, $D$. suzukii adapts easily to environments with high humidity and moderate temperatures (EPPO 2010; Ometto et al. 2013). These environments allow the pest to overwinter when fruit resources are not available and low temperatures are not optimal for fermentation and fly activity (Ometto et al. 2013; Rota-Stabelli et al. 2013). Absence of natural predators and/or effective parasitoids against $D$. suzukii, as well as competitors for fresh fruits (Chabert et al. 2012; Rota-Stabelli et al. 2013), facilitates its establishment in the invaded habitats. Finally, D. suzukii shows a high reproductive rate and rapid developmental rate which results in 7-15 generations per year, depending on the weather conditions (Tochen et al. 2014).

Drosophila suzukii has caused substantial yield and revenue losses in agricultural systems. In the USA (California, Oregon and Washington), losses were estimated around \$511.3 million annually at $20 \%$ damage of strawberries, blueberries, raspberries, blackberries and cherries in 2008 (Bolda et al. 2010; Goodhue et al. 2011; Walsh et al. 2011). Increased costs owing to monitoring and management programs of the pest could also decrease revenue. Regulatory restrictions applied on shipments from infested areas (e.g., quarantine) could lead to significant economic impact. Residual pesticide levels exceeding tolerated limits in fruits from infested areas or postharvest treatments may also lead to rejection of exported fruits, thus limiting fruit market exploitation (Goodhue et al. 2011; Walsh et al. 2011). As a result, global economic loss for fruit production areas is potentially huge.

Considering the significant and rapidly growing agricultural costs generated by the worldwide invasion of $D$. suzukii, we review the knowledge gained so far about the tools that have been deployed to combat this pest. Following a brief review of the current management practices, the classical biological control procedures, we discuss innovative biological control methods and their potential as management solutions for facing the challenge posed by $D$. suzukii.

\section{Pest management: current state and perspectives}

Drosophila suzukii has become a key economic pest, and therefore the development of efficient monitoring and management tools is deemed indispensable. Understanding the pest's invasion mechanisms and gaining higher resolution on its biology are needed to improve management practices (Bahder et al. 2015; Lee et al. 2011a, b). The diverse array of alternate host fruits used by $D$. suzukii and its extreme polyphagy behavior contribute to its persistence in distinct geographic areas, thus escalating its effective management into a challenge (Diepenbrock and Burrack 2017; Lee et al. 2011a, b). Currently several control methods, such as the classical chemical control, are applied worldwide to manage this pest. Nevertheless, these methods proved to be either non-effective or non-cost-effective or with limited applicability due to regulatory restrictions. In the following sections, we address biological and innovative pest management approaches and discuss their application potential and drawbacks.

\section{Biological control}

Given legitimate concerns over the risks and limitations of using a chemical control method, research efforts have already been focused on the development of environmentally sound and sustainable methods. There is a wide variety of biocontrol agents including fungi, bacteria, viruses and natural enemies of the pest that could be employed in the control programs for D. suzukii.

\section{Natural enemies}

Natural enemies of insect pests are endemic species that occur abundantly in agricultural fields. Natural enemies including pathogens, predators and parasitoids can be specialists or generalists, and they can induce a high level of mortality in their hosts (Flint and Dreistadt 1998). Biological control approaches based on arthropod natural enemies are currently studied and developed worldwide.

Parasitoid species are insects attacking other arthropods in the egg, larval or pupal developmental stages. They develop inside, or on the surface of the egg, larvae or pupae, and consume the host tissues during their development (Godfray 1994). Various Drosophila species are subjected to strong selective pressures by egg, larval and pupal parasitoids which play a key role in their population suppression. Most studies agree that Drosophila parasitoids induce a high rate of mortality on their host populations although the level of parasitism varies with breeding sites, local conditions and seasons (Fleury et al. 2009). Studies on natural parasitoid enemies of $D$. suzukii in its invaded regions have shown that parasitism rates are limited, and thus their use is nonefficient for population suppression (Chabert et al. 2012; Daane et al. 2016; Miller et al. 2015). This is attributed to the fact that $D$. suzukii exhibits a high level of resistance to the majority of the larval parasitoids tested, associated to a highly efficient cellular immune system (Poyet et al. 2013; 
Kacsoh and Schlenke 2012). However, a recent study by Rossi Stacconi et al. (2015) showed that Italian populations of Leptopilina heterotoma (Hymenoptera: Figitidae) were able to overcome the encapsulation process by $D$. suzukii under standard laboratory conditions, a fact that could be attributed to the high virulence level of the wild parasitoid population collected in Italy (Rossi Stacconi et al. 2015). In contrast, generalist pupal parasitoids (e.g., Pachycrepoideus vindemiae and Trichopria c.f. drosophilae) were able to develop on $D$. suzukii, at least under laboratory conditions (Chabert et al. 2012; Daane et al. 2016; Miller et al. 2015; Rossi Stacconi et al. 2015; Wang et al. 2016). Kacsoh and Schlenke (2012) used a diverse panel of parasitoid wasps and found that $D$. suzukii was able to survive infection due to the production of a constitutively high hemocyte level. High hemocyte loads are involved in encapsulation of parasitoid eggs and enable D. suzukii larvae to produce a vigorous immune response (Kacsoh and Schlenke 2012). Moreover, spontaneous parasitization of D. suzukii by $P$. vindemiae has been recently reported suggesting a gradual adaptation of the local fauna to the new invader (Rossi-Stacconi et al. 2013). In field-sampling studies in Japan, three larval endoparasitoids were reported to develop on D. suzukii, Asobara japonica (Hymenoptera: Braconidae), G. xanthopoda and Leptopilina japonica japonica (Hymenoptera: Figitidae) (Daane et al. 2016; Kasuya et al. 2013; Mitsui et al. 2007). Ongoing studies on biological control of $D$. suzukii by parasitoids are now focusing on the description of the efficiency of parasitoid species in the native area.

Progressively, government regulations require the development of host-specialized biological control agents. Consequently, a diverse array of other natural enemies including predators, entomopathogenic fungi and nematodes which are commercially available was evaluated for their ability to reduce D. suzukii adults and larvae survival (Woltz et al. 2015; De Ro 2016). Our current knowledge suggests that $D$. suzukii suppression by these enemies was insufficient due to low predation and infection rates, low residual activity or decreased efficiency in field trials. Taken together, extensive field studies and detailed evaluations are required to identify a novel strategy based on introduction and establishment of natural enemies of D. suzukii from its native range for a long-term control and determine their effectiveness and safety with regard to nontarget species.

\section{Innovative biological control methods}

\section{Sterile insect technique (SIT)}

The sterile insect technique (SIT) is a species-specific and environment-friendly method of pest population suppression or eradication (Fig. 2a). The SIT relies on repetitive releases of mass-produced sterile insects (Dyck et al. 2005). The method is based on the sterilization of males (although releases of both sterile males and females have been successfully used), mainly using ionizing radiation which causes dominant lethal mutations in the sperm. In brief, the SIT comprises the following steps: (a) the target species is mass reared, (b) males are separated, when feasible, and sterilized and (c) released in the target area. A sufficient number of sterile males to create an overflow ratio over a period of time are released, and they are expected to compete with wild males and mate with wild females (Dyck et al. 2005). Mating results in infertile eggs and the developing zygotes die during early embryogenesis, thus inducing sterility in the wild females. Therefore, over time, the target population declines or it is potentially eradicated (Knipling 1979).

Effectiveness of SIT is undoubtedly associated with the ability of irradiated males to compete with wild males for mating with wild females. The competitiveness of released sterile males might be impacted by the insect strain and the rearing method, radiation sterilization, marking, stress during cold storage, shipment to the release site and release procedure (Dyck et al. 2005). Therefore, it is essential that the impact of the domestication, irradiation dose, as well as all other components of the SIT package, on emergence rate, adult longevity and mating competitiveness is checked and assessed prior to field application (Dyck et al. 2005; Zhang et al. 2016). Performance of sterile males is not the only critical factor that could affect success of SIT. In any SIT program, the number of released sterile males must surpass the number of wild males in the release area to compensate any negative effect associated with domestication, mass rearing, storage and their overall handling so that they mate with wild females allowing introduction of sufficient sterility into the wild population (Barnes et al. 2015; Dyck et al. 2005; Vreysen 2006). The same is true for any population suppression program, no matter if it is based on classical genetic, transgenic or symbiont-based approaches.

Apart from being an environmentally sound biological control approach, the SIT can be easily integrated with other biological control strategies (parasitoids, predators and pathogens). It is a species-specific method, and the release can be performed from the air thus overcoming any topography limitations. Successful development and application of an SIT operational program depends on: (a) the target population being at low levels; (b) extensive knowledge on the genetics, biology and ecology of the target pest being available before the application; (c) mass-rearing facilities being available and capable of providing large numbers of high-quality sterile insects; (d) a release technology having been developed, and the sterile individuals being efficiently monitored; (e) the releases being applied on an area-wide basis covering the whole pest population and (f) the released 


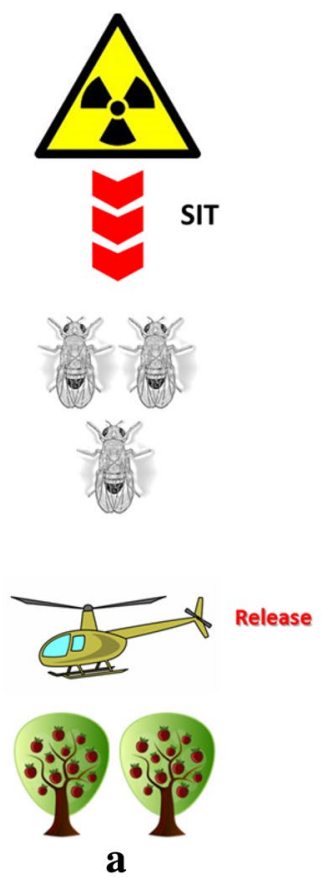

$\mathbf{a}$

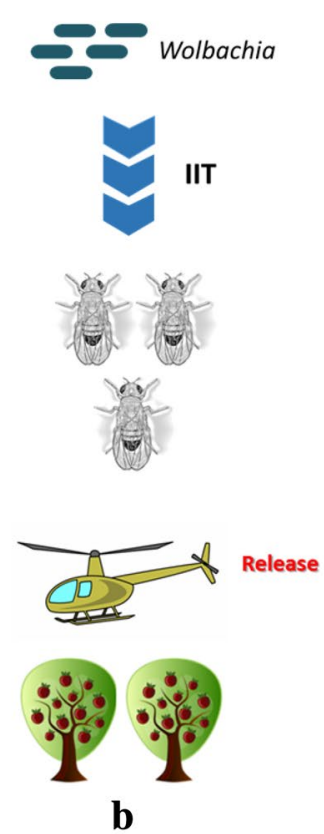

b

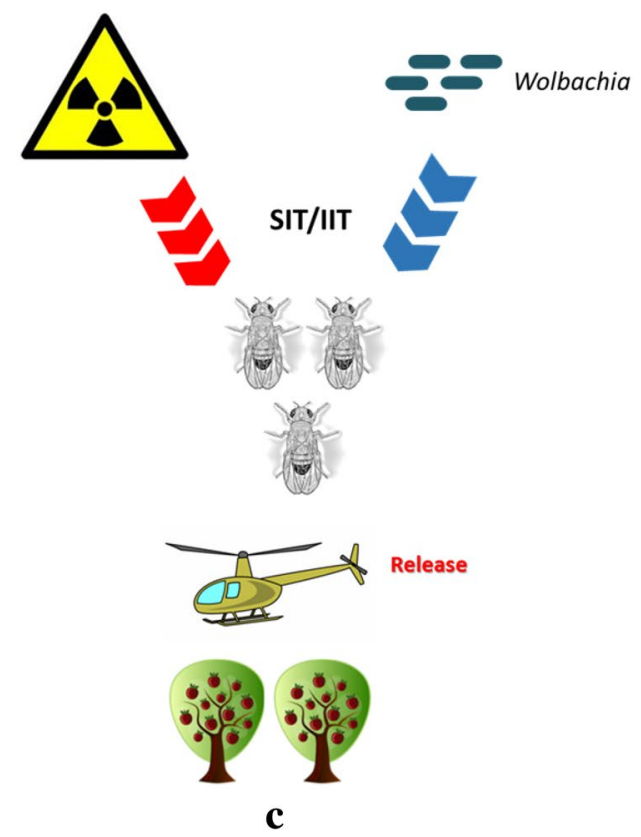

Fig. 2 a Sterile insect technique (SIT). Males are sterilized by the application of irradiation, $\mathbf{b}$ the incompatible insect technique (IIT). Males are sterilized by Wolbachia trans(infection), c combination of

sterile individuals not causing any side effects on humans or the environment (Barnes et al. 2015; Vreysen 2006).

The SIT has proven to be a powerful control tool when applied as part of an area-wide integrated pest management (AW-IPM) approach for the creation of pest-free areas or areas of low pest prevalence (Vreysen 2006). The use of the SIT was initially put into practice in the USA, and it was subsequently developed and applied worldwide by the Joint Food and Agriculture Organization of the United Nations/ International Atomic Energy Agency (FAO/IAEA) Programme on Nuclear Techniques in Food and Agriculture and collaborators (Barnes et al. 2015; Bourtzis and Robinson 2006; Dyck et al. 2005; Vreysen 2006).

The SIT has been refined over many decades, and renewed interest has recently emerged to use it for the population control of human diseases vectors (Bourtzis et al. 2016). Several successful applications of the method have been reported worldwide including the control of key insect pests such as the screwworm fly, the tsetse flies, fruit flies, Lepidoptera (moths) and disease vectors of livestock and humans (Barnes et al. 2015; Bourtzis et al. 2016; Calla et al. 2014; Lees et al. 2015; Munhenga et al. 2016; Pereira et al. 2013; Vreysen et al. 2014; Zhang et al. 2015a). The majority of the SIT programs have been applied for the control of fruit fly species as they represent one of the major insect groups of economic importance (FAO/IAEA 2013, https:// nucleus.iaea.org/sites/naipc/dirsit/; Pereira et al. 2013).

SIT and IIT. Male sterility is due to both irradiation and Wolbachia infection. In all three cases $(\mathbf{a}-\mathbf{c})$, males are released in the field to sterilize the wild females of the targeted population

The acknowledged deliverables of these applications have encouraged researchers to focus on ways to improve the performance of mass-reared sterile males as well as the handling and release methods. Significant knowledge acquired from SIT applications on the genera Anastrepha, Bactrocera and Ceratitis can be transferred partly or entirely to other insect pest species control programs (Pereira et al. 2013).

The rapid dispersal of $D$. suzukii and its subsequent impacts on crops encourage the development of a biocontrol method with a SIT component. Radiation biology experiments are currently ongoing on $D$. suzukii, and first results have shown that $X$-ray radiation can inhibit the development of all stages (egg, larva, pupa and adult) of D. suzukii and induce adult sterility (Follett et al. 2014; Kim et al. 2016). Nevertheless, there are some reasonable concerns about the feasibility of SIT for this pest considering its high fecundity and the recurrent immigration of flies into the crop that are not completely confined. The short generation time of $D$. suzukii indicates that SIT management should be intensive, otherwise there is a risk that the population will recover rapidly. In addition, control of large field populations of $D$. suzukii poses an extra challenge for SIT. In our opinion, greenhouses and other confined locations seem to provide an ideal environment for the biocontrol of $D$. suzukii by using the SIT. The exclusion netting high tunnels could be promising candidates for the implementation of SIT. Recent studies on plastic- and mesh-covered tunnels have shown that 
D. suzukii populations are significantly decreased in these confined areas, not only due to their physical exclusion, but also because of the unfavorable microclimate that is created in these locations (Rogers et al. 2016). Although complete exclusion is not achievable solely by this technique, its combination with SIT could increase the biocontrol levels of $D$. suzukii, thus limiting the use of insecticides. An additional challenge is that an adequate sexing system is not available for $D$. suzukii, and this means that both males and females will be included in the mass-reared and released flies. Bisexual SIT has been successfully used in the past; however, male only releases have been shown to be by far more costeffective and efficient (Rendon et al. 2000).

\section{Incompatible insect technique (IIT)}

Wolbachia is a widespread endosymbiont of arthropods and filarial nematodes. Wolbachia can act as both a parasite and a mutualist, but it is best known for its ability to manipulate their host reproduction (for a review see Werren 1997). Four distinct reproductive alterations have been described in arthropods: feminization, parthenogenesis, male killing and cytoplasmic incompatibility (Saridaki and Bourtzis 2010; Werren et al. 2008). Collectively, these phenotypes are commonly referred to as "reproductive parasitism," and they increase the frequency of infected females in the host population either by inducing a female-biased sex-ratio in the offspring of infected females, or by reducing the female production by uninfected females (Engelstädter and Hurst 2009).

Among the reproductive abnormalities associated with Wolbachia infections, cytoplasmic incompatibility (CI) is the most prominent one. Wolbachia induces modification of the paternal nuclear material which results in failure of progeny to develop unless the same Wolbachia strain(s) is/ are present in the egg and exert(s) the respective rescue function(s) (Bourtzis et al. 1998; Werren 1997; Zabalou et al. 2008). Wolbachia's ability to manipulate the host reproductive system along with its great pandemic has largely been recognized as potential environmental-friendly biocontrol agent. The incompatible insect technique (IIT) employs the symbiont-associated (e.g., Wolbachia) reproductive incompatibility as a biopesticide for the control of insect pests and disease vectors (Fig. 2b). The approach is quite similar to SIT and includes repeated, inundative releases of sterile males in the targeted field population (Berasategui et al. 2016; Bourtzis 2008; Zabalou et al. 2004, 2009). Intensive research in IIT has been performed for several insect pests and disease vectors including Ceratitits capitata, Rhagoletis cerasi, the tsetse fly, Culex pipiens, Aedes albopictus and Culex quinquefasciatus (Alam et al. 2011; Atyame et al. 2011, 2015; Bourtzis et al. 2014; Neuenschwander et al. 1983; Zabalou et al. 2004, 2009; Zhang et al. 2015a), and significant attempts to use IIT against wild populations of disease vectors have been applied for the mosquito Aedes polynesiensis (O'Connor et al. 2012).

One of the main points of this technique is that, contrary to SIT that allows both sexes to be released as long as they are sterile, this is not possible for IIT which requires strict male release. Indeed, the accidental release of females infected by Wolbachia may result in the replacement of the targeted population by a population carrying the Wolbachia infection. Providing that IIT produced females are compatible with the wild males, the success of IIT could be compromised, since the Wolbachia-infected females would be compatible with either the wild or the released males (Berasategui et al. 2016; Bourtzis 2008; O'Connor et al. 2012). Therefore, IIT requires the development of an efficient method for sexing in order to strictly release infected males. Sexing can be achieved by different techniques like phenotypic sorting or genetic-sexing methods based on classical genetic or molecular methods. However, these separation methods are not available for all target species. In addition, there are concerns about the use of GMOs in the European Union.

Although Wolbachia infections are highly prevalent in the drosophilids, CI is not induced by all Wolbachia strains (Hoffmann et al. 1996). However, there is evidence that Wolbachia can engage in mutualistic relationships (Zug and Hammerstein 2015) and it has been shown to provide a broad spectrum of beneficial effects to its native hosts including protection against viral, microbial, fungal pathogens and parasitoids (Bian et al. 2013; Cattel et al. 2016b; Fytrou et al. 2006; Kambris et al. 2010; Martinez et al. 2012, 2014; Moreira et al. 2009; Teixeira et al. 2008; Zindel et al. 2011; Zug and Hammerstein 2015) and increase in host longevity and fecundity (Zug and Hammerstein 2015) which probably explains its pandemic nature (LePage and Bordenstein 2013).

Previous studies reported that $D$. suzukii is infected with a strain of Wolbachia called $w$ Suz that is present in intermediate prevalence in European and American populations (Cattel et al. 2016a; Hamm et al. 2014; Ometto et al. 2013; Siozios et al. 2013). $w$ Suz does not induce a significant level of CI in D. suzukii (Cattel et al. 2016a; Hamm et al. 2014). However, Wolbachia endosymbionts inducing CI can be introduced into a novel host, either by back-crossing experiments or by transinfection, and express high levels of CI (Zabalou et al. 2008). This concept has been studied in insect pests and disease vectors for the suppression of natural populations (Laven 1967; O'Connor et al. 2012; Zabalou et al. 2004; Zhang et al. 2015b). Research work has been performed in this field for D. suzukii, and two Wolbachia strains have been identified as potential candidates for developing the IIT in D. suzukii. Both strains were identified using the transinfection approach, and they induce a very high level of 
$\mathrm{CI}$ in this pest regardless of the presence of $w \mathrm{Suz}$ in females (Mouton et al., personal communication). However, it is critical to address any questions related to host fitness and mating competitiveness of the Wolbachia-infected D. suzukii males under semi-field conditions prior to the deployment of this approach to a large-scale operational program (O'Connor et al. 2012; Zhang et al. 2015a). As discussed above for SIT, male competitiveness in an IIT program may be impacted by the rearing methods and processes, cold storage, shipping and release approaches, but also by the introduction of new Wolbachia strains as in the case of transinfected lines. A potential IIT application would first and foremost require a thorough biological characterization of the host-bacterial symbiotic association. The Wolbachia strain and the host nuclear background are important factors for the expression of CI. Previous studies have suggested that the genetic background of the host is actively involved in the expression of different Wolbachia phenotypes, affecting also the Wolbachia density. This means that ideally the genomic background of the mass-reared insects should be the same with the one in the target field population. In addition, infection with one or more Wolbachia strains could impact the fitness and sexual behavior of host insects, leading in negative effects on the host sexual competitiveness and fitness traits (Bourtzis et al. 2014; Mouton et al. 2007). Given the above, mass-reared insect lines should be evaluated for any potential impacts of the Wolbachia symbiont and the genetic variability of the host before including IIT in an integrated control approach.

\section{Combination of SIT/IIT for D. suzukii management}

A promising alternative approach for the biological control of D. suzukii is coupling SIT with IIT (Fig. 2c). In general, female insects are more sensitive to radiation than male insects in terms of the induction of sterility, and it may be possible to identify a minimum dose of radiation that leads to complete sterility in females (Bourtzis and Robinson 2006; Zhang et al. 2015a, 2016). As a result, any accidentally released Wolbachia-infected females will be sterile and the risk of population replacement is reduced (Bourtzis et al. 2014, 2016; Brelsfoard et al. 2009; Lees et al. 2015). In such a system, the released cytoplasmically incompatible males could also receive a low dose of radiation to ensure complete sterility of females that were not removed. In this case, the sterility of released males would be due to both Wolbachia and irradiation, while the female sterility would only be caused by irradiation. Stress accumulated throughout the rearing, handling, storage, transport and release processes may affect the biological quality of the released males (Dyck et al. 2005). Less competitive males in the field would result in lower induction of sterility in the field females. The combination of SIT with IIT may offer a way out of this, as the released males will be infected with Wolbachia and thus a lower irradiation dose can be applied that will allow for more competitive males. This combined strategy could in principle be applied to any targeted species for which an adequate sexing system is not available. Integration of such a protocol combining low irradiation dose with CI has proved to be an efficient strategy in programs targeting the population suppression of Aedes albopictus (Zhang et al. 2015a, b, 2016).

\section{Requirements for SIT and/or IIT}

Before the application of an SIT and/or IIT program against D. suzukii, it is, nevertheless, important to consider potential limiting factors that may render the program ineffective.

\section{Laboratory domestication and mass rearing}

Apart from the factors affecting mass rearing, the process itself requires industrial-scale equipment and protocol that will allow for the mass production of high-quality sterile $D$. suzukii insects in a cost-effective manner. Another challenge is to develop an economic viable artificial larval and adult diet. The quality of the sterile insects should be continuously monitored to ensure that the desirable biological traits are maintained.

Rearing is a crucial step for SIT and IIT, and the initial fly material used in the rearing process as well as the genomic changes/adaptations is important factors regarding biological quality and consequently release of the manipulated fly specimens (Gilchrist et al. 2012). It is known that within some generations populations can adapt to the mass-rearing environment producing individuals which may significantly differ from their wild counterparts (Gilchrist et al. 2012; Gilligan and Frankham 2003). Several life history traits could be affected during the laboratory adaptation process including reduction in developmental time, lifespan, dispersal ability and stress resistance, as well as early fertility and increased fecundity (Gilchrist et al. 2012; Hoffmann et al. 2001; Raphael et al. 2014). Several studies have reported that genetic diversity loss may occur rapidly during the early generations of domestication (Gilchrist et al. 2012; Raphael et al. 2014; Zygouridis et al. 2014). Results from Gilchrist et al. (2012) in Bactrocera tryoni concur with other studies in Bactrocera oleae documenting the loss of genetic diversity in captive populations (Zygouridis et al. 2014). This genetic issue and the associated phenotypic effects may severely compromise the success of SIT and IIT programs as the fly quality in the $D$. suzukii mass-rearing facility may be severely jeopardized. Thus, it is required to develop a strategy that will allow maintaining genetic diversity, biological quality and competiveness. 
Symbiotic bacteria have shown to affect several aspects of the biology, physiology, nutrition and ecology including reproduction and mating behavior of their insect hosts in diverse ways (Augustinos et al. 2015; Bourtzis and Miller 2003, 2006, 2009; Douglas 2011; Eleftherianos et al. 2013; Engel and Moran 2013; Koukou et al. 2006; Miller et al. 2010; Sharon et al. 2010; Weiss and Aksoy 2011; ZchoriFein and Bourtzis 2011). Drosophila species is associated with taxonomically restricted microbial communities compared to mammals, with only four bacterial families being the dominant taxa (Broderick and Lemaitre 2012; Chandler et al. 2011; Corby-Harris et al. 2007; Erkosar et al. 2013; Wong et al. 2013). Several factors influence the microbiota composition including environmental conditions and habitats, life cycle stages, host age and more especially diet (Chandler et al. 2011; Erkosar et al. 2013; Staubach et al. 2013; Yun et al. 2014). Diet proved to be a driving factor in shaping the gut microbiome diversity (Chandler et al. 2011). A specific diet determines which microbes are able to colonize this environment. As a result, most of the bacteria characterized in laboratory-reared Drosophila populations are not the most abundant in wild populations, and vice versa (Chandler et al. 2011; Staubach et al. 2013). These observations may explain why the fitness of some laboratory-adapted populations is not comparable to that of natural populations.

The biological quality of the mass-produced insects is of major importance for SIT and IIT applications, and its improvement in a mass-rearing facility would result in enhancement of the efficacy of SIT and/or IIT applications. Mass rearing and/or irradiation may affect the gut bacterial community structure of insects, and this may also impact mating competitiveness of sterile males (Ben Ami et al. 2010; Hamden et al. 2013). Similarly, several studies have shown that Wolbachia may be associated with mating isolation phenomena (Koukou et al. 2006; Miller et al. 2010). Since insect-associated microbiota seems to play a major role in fly quality, it is important to identify the factors that could alter and/or modify the composition of the intestinal symbionts and consequently reduce the overall fitness of the sterile males. In addition, the use of probiotics (originating from endogenous gut-associated bacterial species) should be explored, as a means to improve rearing efficiency and mating competitiveness as shown for medfly (Augustinos et al. 2015; Gavriel et al. 2011).

\section{Irradiation protocol}

Irradiation dose required for complete male sterility may affect biological quality and mating competitiveness of $D$. suzukii. The optimal conditions, developmental stage and dose for irradiation-induced male sterility should be determined to minimize potential negative effects, while the use of probiotics could ameliorate them as shown for medfly (Gavriel et al. 2011). Applying the SIT to D. suzukii involves irradiation during a narrow time window at the late pupal stage to induce atrophy of the reproductive organs, therefore inducing reproductive sterility without affecting reproductive behavior, and then release into the target area where the sterile males sexually compete with their wild counterparts. An irradiation protocol must be thoroughly developed and tested to ensure a high degree of confidence that the process will properly sterilize the insects. For the combined SIT/ IIT approach, it is also important to determine the minimum optimal dose for complete sterilization of female $D$. suzukii that will not influence the male mating competitiveness. Therefore, it is important that this dose is significantly below that normally required for full male sterility (Lees et al. 2015; Zhang et al. 2016).

The SIT and IIT programs also need to ensure that, once in the field, the sterile males compete effectively with wild males and mate with wild females and successfully transfer their sperm. Effective methods for monitoring and providing timely feedback on the quality and competitiveness of sterile fruit flies are critical to the success of SIT programs. The quality of the sterile mass-reared insects and the mating competitiveness - as measured by their ability to induce sterility in field females - with the wild counterparts are critical factors that should be measured and assessed using appropriate procedures (Dyck et al. 2005). Quality control protocols at laboratory and semi-field conditions level are required for the evaluation of flight ability and effectiveness of the mass-reared, irradiated and released sterile $D$. suzukii. The Joint FAO/IAEA Insect Pest Control Laboratory has developed a quality control manual for fruit flies (FAO/IAEA/ USDA 2014). The manual includes procedures for product quality control (QC) for mass-reared and sterilized flies as well as handling and packaging methods of pupae intended to be used in SIT programs. These procedures involve series of tests that measure pupae weight, emergence, sterility, longevity, flight ability, sexual competitiveness and survival under stress. The quality of the mass-produced sterile insects will determine the ratio required for the population suppression.

\section{Management of thermal tolerance}

Low-temperature treatment is an integral part of the rearing or release protocols in IPM programs (Colinet and Boivin 2011; Enkerlin 2007). For both SIT and IIT, efficient deployment of insects is achieved when their release coincides with the appearance of the pests, and there is often a timing gap between production and release. The ability to cold-store insects without loss of performance and to mobilize them quickly upon demand is thus essential for a viable biological control using SIT and/or IIT. Mass-reared insects are often 
exposed to low temperature for immobilization and handling during rearing process. Long-distance shipping from rearing facilities to release sites is also performed under low temperature. Finally, temperature within the release site (e.g., greenhouse) may contrast with rearing conditions and may be stressful to released insects (being too high or too low). This latter issue can be mitigated by application of thermal conditioning protocols before release to prevent thermal stress-induced mortality. In consequence, a successful application of SIT and/or IIT requires large basic knowledge on thermal biology of the target insect in order to develop protocols to manipulate its thermal tolerance.

Most recent studies on D. suzukii cold tolerance were designed to understand overwintering strategy in newly infested cold regions, in order to better predict invasion potential or winter survival probability (Dalton et al. 2011; Rossi-Stacconi et al. 2016; Shearer et al. 2016; Stephens et al. 2015; Wallingford and Loeb 2016; Zerulla et al. 2015). The recent literature shows that $D$. suzukii is freeze intolerant and chill susceptible (Dalton et al. 2011; Jakobs et al. 2015; Kimura 2004; Plantamp et al. 2016; Ryan et al. 2016), but possesses a large thermal tolerance plasticity, which likely favors its overwintering success (Jakobs et al. 2015). This large plasticity could be exploited to modulate D. suzukii thermal tolerance via classical acclimation protocols, e.g., pre-exposure to sublethal conditions (Colinet and Hoffmann 2012). Drosophila suzukii is supposed to overwinter as adult dark winter morph (Kanzawa 1936; Shearer et al. 2016; Stephens et al. 2015; Toxopeus et al. 2016; Wallingford et al. 2016). This morph is characterized by an arrest of reproduction and an increased cold tolerance (Shearer et al. 2016; Stephens et al. 2015; Toxopeus et al. 2016; Wallingford and Loeb 2016), but it is not yet clear whether this morph entails a true reproductive diapause or not (Rossi-Stacconi et al. 2016; Toxopeus et al. 2016; Wallingford et al. 2016; Zhai et al. 2016). Understanding how to initiate and arrest its diapause may provide valuable tools for long-term storage. Knowledge of the overwintering biology of $D$. suzukii is also a crucial factor in predicting the size of the summer population in a given area (Rossi-Stacconi et al. 2016). This will allow for more efficient planning of the control methods implementation. For instance, the SIT and IIT approaches that are based on the release of massproduced sterile males could take advantage of the shortage of wild males during late winter/early spring periods. Their implementation at those periods would reduce the competition from the wild males and increase the mating frequency for the sterile males (Rossi-Stacconi et al. 2016). Given the high level of inconsistency in the available data regarding $D$. suzukii mortality at different temperatures, detailed thermobiological data are highly needed (Asplen et al. 2015). To fully appreciate the innate capacity of $D$. suzukii to cope with both cold and heat stress, a comprehensive approach based on tolerance landscape has been proposed by Enriquez and Colinet (2017). The authors found that temperatures below $5-7{ }^{\circ} \mathrm{C}$ were likely not compatible with cold storage, while temperatures above $32{ }^{\circ} \mathrm{C}$ would drastically reduce survival. Thermal survival patterns were also influenced by sex, stage, as well as relative humidity. This basic information is important to develop protocols to manipulate $D$. suzukii thermal tolerance. Undoubtedly, studying thermal biology of $D$. suzukii is essential to facilitate the application of SIT and/or IIT, but other aspects of SIT and/or IIT could be impacted (positively or negatively) by temperature. For instance, lowering metabolic rate with low temperature or promoting generic mechanisms of stress tolerance with preexposures may mitigate off-target irradiation damages and promote post-irradiation performance. Applying mild thermal stress (heat or cold) at some specific stage could trigger antioxidant defenses and lower oxidative damages resulting from irradiation. Such a hormesis approach (i.e., physiological conditioning) has been observed when applying shortterm anoxic conditions before irradiation in the Caribbean fruit fly (López-Martínez and Hahn 2014). Besides, thermal conditions may directly affect Wolbachia load (Mouton et al. 2006, 2007), and consequently, it is important to analyze whether thermal treatments allow maintenance of high level of CI. On the other hand, data coming from the study of Neelakanta et al. (2010) have shown that gut symbionts can enhance the ability of insects to tolerate cold temperatures and overwinter. Acquiring knowledge on basal and induced thermal tolerance of irradiated and Wolbachia-infected $D$. suzukii will also help in defining accurate management practices based on SIT and/or IIT programs.

\section{Conclusions}

Drosophila suzukii has spread across Europe and causes significant economic losses in commercial soft fruits. Its rapid invasive rate in the continent poses a challenge to the development of efficient monitoring and management tools. Drosophila suzukii is a highly prolific species with exceptional biological traits that contribute to its persistence in distinct geographic areas. This fact, combined with its extreme polyphagy behavior, suggests that an AW-IPM program is required for the effective control of the pest. Chemical control tactics are currently the most widespread method used to control $D$. suzukii. Insect resistance to chemicals, frequent applications of insecticides owing to $D$. suzukii's short generation time and concerns about public health are considerable issues that have turned research toward non-chemical, environmentally sound and sustainable approaches. Investment in innovative biological control methods could lead to a reduction in $D$. suzukii's populations not only in cultivated crops, but also in natural niches that are normally neglected 
by chemical approaches. Development of SIT for D. suzukii, as a component of an AW-IPM approach, is expected to significantly contribute to population management, especially in greenhouses and other confined areas, such as exclusion netting high tunnels. Driven by the encouraging results of SIT applications on other pests, research groups have focused their efforts on addressing the challenges related to the method. In the unlikely event that the irradiated sterile males present decreased or insufficient mating competitiveness, employment of IIT as a supplement to SIT is worth considering. This combined strategy could offer a way out of dead ends posed by each method individually. Management of thermal tolerance is a crucial factor that allows cold storage of insects without loss of their performance. Acquiring knowledge on thermal biology of D. suzukii will allow the deployment of thermal tolerance manipulation protocols. As soon as these protocols are mature, the rearing and release processes of SIT or the combined SIT/IIT approaches will profit from them and become more reliable. Whatever the method to be applied, there are several questions that need to be addressed beforehand and knowledge gaps to shed light on. To this aim, research should be carried out to deploy accurate and well-established management programs to decrease the impact of this invasive pest.

\section{Author contributions}

$\mathrm{KN}$ and $\mathrm{KB}$ organized the review. $\mathrm{KN}$ wrote the review, and $\mathrm{HC}$ contributed in the "Management of thermal tolerance" part. All authors reviewed and provided constructive comments for this manuscript. All authors read and approved the final manuscript.

Acknowledgements This review was supported by the French National Research Agency (ANR-15-CE21-0017-01) and the Austrian Science Fund (FWF-I2604-B25).

\section{Compliance with ethical standards}

Conflict of interest The authors declare that they have no conflict of interest.

Ethical approval This article does not contain any studies with animals performed by any of the authors.

Informed consent Informed consent was obtained from all co-authors included in the study.

Open Access This article is distributed under the terms of the Creative Commons Attribution 4.0 International License (http://creativecommons.org/licenses/by/4.0/), which permits unrestricted use, distribution, and reproduction in any medium, provided you give appropriate credit to the original author(s) and the source, provide a link to the Creative Commons license, and indicate if changes were made.

\section{References}

Adrion JR, Kousathanas A, Pascual M, Burrack HJ, Haddad NM, Bergland AO, Machado H, Sackton TB, Schlenke TA, Watada M, Wegmann D, Singh ND (2014) Drosophila suzukii: the genetic footprint of a recent, worldwide invasion. Mol Biol Evol 31:3148-3163. https://doi.org/10.1093/molbev/msu246

Alam U, Medlock J, Brelsfoard C, Pais R, Lohs C, Balmand S, Carnogursky J, Heddi A, Takac P, Galvani A, Aksoy S (2011) Wolbachia symbiont infections induce strong cytoplasmic incompatibility in the tsetse fly Glossina morsitans. PLoS Pathog 7:e1002415. https://doi.org/10.1371/journal.ppat.1002415

Asplen MK, Anfora G, Biondi A et al (2015) Invasion biology of spotted wing Drosophila (Drosophila suzukii): a global perspective and future priorities. J Pest Sci 88(469):494. https:// doi.org/10.1007/s10340-015-0681-z

Atyame CM, Delsuc F, Pasteur N, Weill M, Duron O (2011) Diversification of Wolbachia endosymbiont in the Culex pipiens mosquito. Mol Biol Evol 28:2761-2772. https://doi.org/10.1093/ molbev/msr083

Atyame CM, Cattel J, Lebon C, Flores O, Dehecq JS et al (2015) Wolbachia-based population control strategy targeting Culex quinquefasciatus mosquitoes proves efficient under semi-field conditions. PLoS ONE 10:e0119288. https://doi.org/10.1371/ journal.pone.0119288

Augustinos AA, Kyritsis GA, Papadopoulos NT, Abd-Alla AMM, Cáceres C et al (2015) Exploitation of the Medfly gut microbiota for the enhancement of sterile insect technique: use of Enterobacter sp. in larval diet-based probiotic applications. PLoS ONE 10:e0136459. https://doi.org/10.1371/journal. pone. 0136459

Bahder BW, Bahder LD, Hamby KA, Walsh DB, Zalom FG (2015) Microsatellite variation of two Pacific coast Drosophila suzukii (Diptera: Drosophilidae) populations. Environ Entomol 44:14491453. https://doi.org/10.1093/ee/nvv117

Barnes BN, Hofmeyr JH, Groenewald S, Conlong DE, Wohlfarter M (2015) The sterile insect technique in agricultural crops in South Africa: a metamorphosis.... but will it fly? Afr Entomol 23:1-18. https://doi.org/10.4001/003.023.0103

Ben Ami E, Yuval B, Jurkevitch E (2010) Manipulation of the microbiota of mass-reared Mediterranean fruit flies Ceratitis capitata (Diptera: Tephritidae) improves sterile male sexual performance. ISME J 4:28-37. https://doi.org/10.1038/ismej.2009.82

Berasategui A, Shukla S, Salem H, Kaltenpoth M (2016) Potential applications of insect symbionts in biotechnology. Appl Microbiol Biotechnol 100:1567-1577. https://doi.org/10.1007/ s00253-015-7186-9

Bian G, Joshi D, Dong Y, Lu P, Zhou G, Pan X, Xu Y, Dimopoulos G, Xi Z (2013) Wolbachia invades Anopheles stephensi populations and induces refractoriness to Plasmodium infection. Science 340:748-751. https://doi.org/10.1126/science.1236192

Bolda M, Goodhue R, Zalom FG (2010) Spotted wing Drosophila: potential economic impact of a newly established pest. Agric Resour Econ Update 13:5-8

Bourtzis K (2008) Wolbachia-based technologies for insect pest population control. In: Aksoy S (ed) Transgenesis and the management of vector-borne disease, vol 627. Springer, New York, pp 104-113

Bourtzis K, Miller TA (2003) Insect symbiosis, vol 1. CRC Press, Boca Raton

Bourtzis K, Miller TA (2006) Insect symbiosis, vol 2. CRC Press, Boca Raton

Bourtzis K, Miller TA (2009) Insect symbiosis, vol 3. CRC Press, Boca Raton 
Bourtzis K, Robinson AS (2006) Insect pest control using Wolbachia and/or radiation. In: Bourtzis K, Miller TA (eds) Insect symbiosis, vol 2. CRC Press, Boca Raton, pp 225-246

Bourtzis K, Dobson SL, Braig HR, O’Neill SL (1998) Rescuing Wolbachia have been overlooked. Nature 391(6670):852-853

Bourtzis K, Dobson SL, Xi Z, Rasgon JL, Calvitti M, Moreira LA et al (2014) Harnessing mosquito-Wolbachia symbiosis for vector and disease control. Acta Trop 132(Suppl):S150-S163. https://doi. org/10.1016/j.actatropica.2013.11.004

Bourtzis K, Lees RS, Hendrichs J, Vreysen MJ (2016) More than one rabbit out of the hat: radiation, transgenic and symbiontbased approaches for sustainable management of mosquito and tsetse fly populations. Acta Trop 157:115-130. https://doi. org/10.1016/j.actatropica.2016.01.009

Brelsfoard CL, St Clair W, Dobson SL (2009) Integration of irradiation with cytoplasmic incompatibility to facilitate a lymphatic filariasis vector elimination approach. Parasit Vectors 2:38. https://doi. org/10.1186/1756-3305-2-38

Broderick NA, Lemaitre B (2012) Gut-associated microbes of Drosophila melanogaster. Gut Microbes 3:307-321

Calabria G, Máca J, Bachli G, Serra L, Pascual M (2012) First records of the potential pest species Drosophila suzukii (Diptera: Drosophilidae) in Europe. J Appl Entomol 136:139-147. https://doi. org/10.1111/j.1439-0418.2010.01583.x

Calla B, Hall B, Hou S, Geib SM (2014) A genomic perspective to assessing quality of mass-reared SIT flies used in Mediterranean fruit fly (Ceratitis capitata) eradication in California. BMC Genom 15:98. https://doi.org/10.1186/1471-2164-15-98

Cattel J, Kaur R, Gibert P, Martinez J, Fraimout A, Jiggins F, Andrieux T, Siozios S, Anfora G, Miller W, Rota-Stabelli O, Mouton L (2016a) Wolbachia in European populations of the invasive pest Drosophila suzukii: regional variation in infection frequencies. PLoS ONE 11:e0147766. https://doi.org/10.1371/journal. pone. 0147766

Cattel J, Martinez J, Jiggins F, Mouton L, Gibert P (2016b) Wolbachiamediated protection against viruses in the invasive pest Drosophila suzukii. Insect Mol Biol 25:595-603. https://doi.org/10.1111/ imb. 12245

Chabert S, Allemand R, Poyet M, Eslin P, Gibert P (2012) Ability of European parasitoids (Hymenoptera) to control a new invasive Asiatic pest, Drosophila suzukii. Biol. Control 63:40-47. https:// doi.org/10.1016/j.biocontrol.2012.05.005

Chandler JA, Lang JM, Bhatnagar S, Eisen JA, Kopp A (2011) Bacterial communities of diverse Drosophila species: ecological context of a host-microbe model system. PLoS Genet 7:e1002272. https://doi.org/10.1371/journal.pgen.1002272

Chireceanu C, Chiriloaie A, Teodoru A (2015) First record of spotted wing drosophila Drosophila suzukii (Diptera: Drosophilidae) in Romania. Rom J Plant Prot 8:86-95

Cini A, Ioriatti C, Anfora G (2012) A review of the invasion of Drosophila suzukii in Europe and a draft research agenda for integrated pest management. Bull Insectol 65:149-160

Colinet H, Boivin G (2011) Insect parasitoids cold storage: a comprehensive review of factors of variability and consequences. Biol Control 58:83-95. https://doi.org/10.1016/j. biocontrol.2011.04.014

Colinet H, Hoffmann AA (2012) Comparing phenotypic effects and molecular correlates of developmental, gradual and rapid cold acclimation responses in Drosophila melanogaster. Funct Ecol 26:84-93. https://doi.org/10.1111/j.1365-2435.2011.01898.x

Corby-Harris V, Pontaroli AC, Shimkets LJ, Bennetzen JL, Habel KE, Promislow DEL (2007) Geographical distribution and diversity of bacteria associated with natural populations of Drosophila. Appl Environ Microbiol 73:3470-3479
Daane KM, Wang XG, Biondi A et al (2016) First exploration of parasitoids of Drosophila suzukii in South Korea as potential classical biological agents. Pest Sci 89:823-835. https://doi.org/10.1007/ s10340-016-0740-0

Dalton DT, Walton VM, Shearer PW, Walsh DB, Caprile J, Isaacs R (2011) Laboratory survival of Drosophila suzukii under simulated winter conditions of the Pacific northwest and seasonal field trapping in five primary regions of small and stone fruit production in the United States. Pest Manag Sci 67:1368-1374. https://doi.org/10.1002/ps. 2280

De Ro M (2016) IPMDROS: Integrated pest management strategies against Drosophila suzukii. Poster session presented at 66th session of EPPO Council, Paris, France

Deprá M, Poppe JL, Schmitz HJ, De Toni DC, Valente VLS (2014) The first records of the invasive pest Drosophila suzukii in the South American continent. J Pest Sci 87:379-383. https://doi. org/10.1007/s10340-014-0591-5

Diepenbrock LM, Burrack HJ (2017) Variation of within-crop microhabitat use by Drosophila suzukii (Diptera: Drosophilidae) in blackberry. J Appl Entomol 141:1-7. https://doi.org/10.1111/ jen. 12335

Douglas AE (2011) Lessons from studying insect symbioses. Cell Host Microbe 10:359-367. https://doi.org/10.1016/j. chom.2011.09.001

Dyck VA, Hendrichs J, Robinson AS (2005) Sterile insect technique: principles and practice in area-wide integrated pest management. Springer, The Netherlands, $\mathrm{p} 787 \mathrm{p}$

Eleftherianos I, Atri J, Accetta J, Castillo JC (2013) Endosymbiotic bacteria in insects: guardians of the immune system? Front Physiol 4:46. https://doi.org/10.3389/fphys.2013.00046

Engel P, Moran NA (2013) The gut microbiota of insects-diversity in structure and function. FEMS Microbiol Rev 37:699-735. https://doi.org/10.1111/1574-6976.12025

Engelstädter J, Hurst GDD (2009) The ecology and evolution of microbes that manipulate host reproduction. Annu Rev Ecol Evol Syst 40:127-149. https://doi.org/10.1146/annurev. ecolsys.110308.120206

Enkerlin W (2007) Guidance for packing, shipping, holding and release of sterile flies in area-wide fruit fly control programmes. FAO Plant production and protection paper 190

Enriquez T, Colinet H (2017) Basal tolerance to heat and cold exposure of the spotted wing Drosophila, Drosophila suzukii. PeerJ 5:e3112. https://doi.org/10.7717/peerj.3112

EPPO (2010) First record of Drosophila suzukii in Italy: addition to the EPPO Alert List. http://archives.eppo.int/EPPOReporting/2010/ Rse-1001.pdf. Accessed 22 Aug 2017

Erkosar B, Storelli G, Defaye A, Leulier F (2013) Host-intestinal microbiota mutualism: learning on the fly. Cell Host Microbe 13:8-14. https://doi.org/10.1016/j.chom.2012.12.004

FAO/IAEA (2013) World-Wide Directory of SIT Facilities (DIR-SIT). https://nucleus.iaea.org/sites/naipc/dirsit/SitePages/WorldWide\%20Directory\%20of\%20SIT\%20Facilities\%20(DIR-SIT). aspx Accessed 22 Feb 2017

FAO/IAEA/USDA (2014) Product quality control for sterile massreared and released tephritid fruit flies, Version 6.0. http://wwwnaweb.iaea.org/nafa/ipc/public/QualityControl.pdf Accessed 22 Feb 2017

Fleury F, Gibert P, Ris N, Allemand R (2009) Ecology and life history evolution of frugivorous Drosophila parasitoids. Adv Parasitol 70:3-44. https://doi.org/10.1016/S0065-308X(09)70001-6

Flint M, Dreistadt SH (1998) Natural enemies handbook: the illustrated guide to biological pest control. Univ Calif Div Agric Nat Res Publ, Oakland, p 3386

Follett PA, Swedman A, Price DK (2014) Postharvest irradiation treatment for quarantine control of Drosophila suzukii 
(Diptera: Drosophilidae) in fresh commodities. J Econ Entomol 107:964-969

Fraimout A, Debat V, Fellous S, Hufbauer RA, Foucaud J et al (2017) Deciphering the routes of invasion of Drosophila suzukii by means of ABC random forest. Mol Biol Evol 34:980-996. https:// doi.org $/ 10.1093 / \mathrm{molbev} / \mathrm{msx} 050$

Fytrou A, Schofield PG, Kraaijeveld AR, Hubbard SF (2006) Wolbachia infection suppresses both host defence and parasitoid counter-defence. Proc Biol Sci 273:791-796

Gavriel S, Jurkevitch E, Gazit Y, Yuval B (2011) Bacterially enriched diet improves sexual performance of sterile male Mediterranean fruit flies. J App Entomol 135:564-573. https://doi. org/10.1111/j.1439-0418.2010.01605.x

Gilchrist AS, Cameron EC, Sved JA, Meats AW (2012) Genetic consequences of domestication and mass rearing of pest fruit fly Bactrocera tryoni (Diptera: Tephritidae). J Econ Entomol 10:1051-1056

Gilligan DM, Frankham R (2003) Dynamics of genetic adaptation to captivity. Conserv Genet 4:189-197. https://doi.org/10.102 3/A:1023391905158

Godfray HCJ (1994) Parasitoids: behavioral and evolutionary ecology. Princeton University Press, Princeton

Goodhue RE, Bolda M, Farnsworth D, Williams JC, Zalom FG (2011) Spotted wing Drosophila infestation of California strawberries and raspberries: economic analysis of potential revenue losses and control costs. Pest Manag Sci 67:1396-1402. https://doi. org/10.1002/ps.2259

Grant JA, Sial AA (2016) Potential of muscadine grapes as a viable Host of Drosophila suzukii (Diptera: Drosophilidae) in blueberry-producing regions of the southeastern United States. J Econ Entomol 109:1261-1266

Grassi A, Giongo L, Palmieri L (2011) Drosophila (Sophophora) suzukii (Matsumura), new pest of soft fruits in Trentino (NorthItaly) and in Europe. IOBC/WPRS Bull 70:121-128

Hamden H, Guerfali MM, Fadhl S, Saidi M, Chevrier C (2013) Fitness improvement of mass-reared sterile males of Ceratitis capitata (Vienna 8 strain) (Diptera: Tephritidae) after gut enrichment with probiotics. J Econ Entomol 106:641-647

Hamm CA, Begun DJ, Vo A, Smith CC, Saelao P, Shaver AO, Jaenike J, Turelli M (2014) Wolbachia do not live by reproductive manipulation alone: infection polymorphism in Drosophila suzukii and D. subpulchrella. Mol Ecol 23(19):4871-4885. https://doi. org/10.1111/mec. 12901

Hauser MS, Gaimari MD (2009) Drosophila suzukii new to North America. Fly Times 43:12-15

Hoffmann AA, Clancy D, Duncan J (1996) Naturally-occurring Wolbachia infection in Drosophila simulans that does not cause cytoplasmic incompatibility. Heredity (Edinb) 76:1-8

Hoffmann AA, Hallas R, Sinclair C, Partridge L (2001) Rapid loss of stress resistance in Drosophila melanogaster under adaptation to laboratory culture. Evolution 55:436-438

Ioriatti C, Walton V, Dalton D, Anfora G, Grassi A, Maistri S, Mazzoni V (2015) Drosophila suzukii (Diptera: Drosophilidae) and its potential impact to wine grapes during harvest in two cool climate wine grape production regions. J Econ Entomol 108:1148-1155. https://doi.org/10.1093/jee/tov042

Jakobs R, Gariepy TD, Sinclair BJ (2015) Adult plasticity of cold tolerance in a continental-temperate population of Drosophila suzukii. J Insect Physiol 79:1-9

Kacsoh BZ, Schlenke TA (2012) High hemocyte load is associated with increased resistance against parasitoids in Drosophila suzukii, a relative of $D$. melanogaster. PLoS ONE 7:e34721. https://doi. org/10.1371/journal.pone.0034721

Kambris Z, Blagborough AM, Pinto SB, Blagrove MS, Godfray HC, Sinden RE, Sinkins SP (2010) Wolbachia stimulates immune gene expression and inhibits plasmodium development in
Anopheles gambiae. PLoS Pathog 6:e1001143. https://doi. org/10.1371/journal.ppat.1001143

Kanzawa T (1936) Studies on Drosophila suzukii Mats. J Plant Prot (Tokyo) 23:66-70, 127-132, 183-191. In: Rev Appl Entomol $24: 315$

Kasuya N, Mitsui H, Ideo S, Watada M, Kimura M (2013) Ecological, morphological and molecular studies on Ganaspis individuals (Hymenoptera: Figitidae) attacking Drosophila suzukii (Diptera: Drosophilidae). Appl Entomol Zool 48:87-92

Kim J, Kim J, Park CG (2016) X-ray radiation and developmental inhibition of Drosophila suzukii (Matsumura) (Diptera: Drosophilidae). Int J Radiat Biol 92:849-854

Kimura MT (2004) Cold and heat tolerance of drosophilid flies with reference to their latitudinal distributions. Oecol 140:442-449

Knipling EF (1979) The basic principles of insect population suppression and management. Agriculture Handbook. USDA No.512 pp. ix +659 pp

Koukou K, Pavlikaki H, Kilias G, Werren JH, Bourtzis K, Alahiotis SN (2006) Influence of antibiotic treatment and Wolbachia curing on sexual isolation among Drosophila melanogaster cage populations. Evolution 60:87-96

Lasa R, Tadeo E (2015) Invasive drosophilid pests Drosophila suzukii and Zaprionus indianus (Diptera: Drosophilidae) in Veracruz, Mexico. Fla Entomol 98:987-988

Laven H (1967) A possible model for speciation by cytoplasmic isolation in the Culex pipiens complex. Bull World Health Organ 37:263-266

Lavrinienko A, Kesäniemi J, Watts PC et al (2017) First record of the invasive pest Drosophila suzukii in Ukraine indicates multiple sources of invasion. J Pest Sci 90:421-429. https://doi. org/10.1007/s10340-016-0810-3

Lee JC, Bruck DJ, Curry H, Edwards D, Haviland DR, Van Steenwyk RA, Yorgey BM (2011a) The susceptibility of small fruits and cherries to the spotted-wing drosophila, Drosophila suzukii. Pest Manag Sci 67:1358-1367. https://doi.org/10.1002/ps.2225

Lee JC, Bruck DJ, Dreves AJ, Ioriatti C, Vogt H, Baufeld P (2011b) In focus: spotted wing drosophila, Drosophila suzukii, across perspectives. Pest Manag Sci 67:1349-1351. https://doi. org/10.1002/ps.2271

Lee JC, Dreves AJ, Cave AM, Kawai S, Isaacs R, Miller JC, Van Timmeren S, Bruck DJ (2015) Infestation of wild and ornamental noncrop fruits by Drosophila suzukii (Diptera: Drosophilidae). Ann Entomol Soc Am 108:117-129

Lees RS, Gilles JR, Hendrichs J, Vreysen MJ, Bourtzis K (2015) Back to the future: the sterile insect technique against mosquito disease vectors. Curr Opin Insect Sci 10:156-162

Lengyel GD, Orosz S, Kiss B, Lupták R, Kárpáti Z (2015) New records and present status of the invasive spotted wing drosophila, Drosophila suzukii (Matsumura, 1931) (Diptera) in Hungary. Acta Zool Acad Sci Hung 61:73-80

LePage D, Bordenstein SR (2013) Wolbachia: can we save lives with a great pandemic? Trends Parasitol 29:385-393. https://doi. org/10.1016/j.pt.2013.06.003

López-Martínez G, Hahn DA (2014) Early life hormetic treatments decrease irradiation-induced oxidative damage, increase longevity, and enhance sexual performance during old age in the Caribbean fruit fly. PLoS ONE 9:e88128. https://doi.org/10.1371/ journal.pone.0088128

Lue C-H, Mottern JL, Walsh GC, Buffington ML (2017) New record for the invasive spotted wing Drosophila, Drosophila suzukii (Matsumura, 1931) (Diptera: Drosophilidae) in Anillaco, Western Argentina. Proc Entomol Soc Wash 119:146-150

Martinez J, Duplouy A, Woolfit M, Vavre F, O’Neill SL, Varaldi J (2012) Influence of the virus LbFV and of Wolbachia in a host-parasitoid interaction. PLoS ONE 7:e35081. https://doi. org/10.1371/journal.pone.0035081 
Martinez J, Longdon B, Bauer S, Chan YS, Miller WJ, Bourtzis K, Teixeira L, Jiggins FM (2014) Symbionts commonly provide broad spectrum resistance to viruses in insects: a comparative analysis of Wolbachia strains. PLoS Pathog 10:e1004369. https:// doi.org/10.1371/journal.ppat.1004369

Miller WJ, Ehrman L, Schneider D (2010) Infectious speciation revisited: impact of symbiont-depletion on female fitness and mating behavior of Drosophila paulistorum. PLoS Pathog 6:e1001214. https://doi.org/10.1371/journal.ppat.1001214

Miller B, Anfora G, Buffington M, Daane KM, Dalton DT, Hoelmer K, Stacconi MVR, Grassi A, Ioriatti C, Loni A et al (2015) Seasonal occurrence of resident parasitoids associated with Drosophila suzukii in two small fruit production regions of Italy and the USA. Bull Insectol 68:255-263

Mitsui H, Van Achterberg K, Nordlander G, Kimura MT (2007) Geographical distributions and host associations of larval parasitoids of frugivorous Drosophilidae in Japan. J Nat Hist 41:1731-1738

Moreira LA, Iturbe-Ormaetxe I, Jeffery JA, Lu G, Pyke AT, Hedges LM, Rocha BC, Hall-Mendelin S, Day A, Riegler M, Hugo LE, Johnson KN, Kay BH, McGraw EA, van den Hurk AF, Ryan PA, O'Neill SL (2009) A Wolbachia symbiont in Aedes aegypti limits infection with dengue, chikungunya, and Plasmodium. Cell 139:1268-1278. https://doi.org/10.1016/j.cell.2009.11.042

Mouton L, Henri H, Boulétreau M, Vavre F (2006) Effect of temperature on Wolbachia density and consequences on cytoplasmic incompatibility. Parasitology 132:49-56

Mouton L, Henri H, Charif D, Boulétreau M, Vavre F (2007) Interaction between host genotype and environmental conditions affects bacterial density in Wolbachia symbiosis. Biol Lett 3:210-213

Munhenga G, Brooke BD, Gilles JR, Slabbert K, Kemp A, Dandalo LC, Wood OR, Lobb LN, Govender D, Renke M, Koekemoer LL (2016) Mating competitiveness of sterile genetic sexing strain males (GAMA) under laboratory and semi-field conditions: steps towards the use of the sterile insect technique to control the major malaria vector Anopheles arabiensis in South Africa. Parasit Vectors. 9:122. https://doi.org/10.1186/s13071-016-1385-9

Neelakanta G, Sultana H, Fish D, Anderson JF, Fikrig E (2010) Anaplasma phagocytophilum induces Ixodes scapularis ticks to express an antifreeze glycoprotein gene that enhances their survival in the cold. J Clin Invest. 120:3179-3190. https://doi. org/10.1172/JCI42868

Neuenschwander P, Russ K, Hoebaus E, Michelakis S (1983) Ecological studies on Rhagoletis cerasi in Crete for the use of the incompatible insect technique. In: Calvalloro R (ed) Fruit flies of economic importance. Proceedings of the CEC/IOBC international symposium Athens, Nov 1982. Balkema, Rotterdam, pp 366-370

O'Connor L, Plichart C, Sang AC, Brelsfoard CL, Bossin HC, Dobson SL (2012) Open release of male mosquitoes infected with a Wolbachia biopesticide: field performance and infection containment. PLoS Negl Trop Dis 6:e1797. https://doi.org/10.1371/ journal.pntd.0001797

Ometto L, Cestaro A, Ramasamy S, Grassi A, Revadi S, Siozios S, Moretto M, Fontana P, Varotto C, Pisani D, Dekker T, Wrobel N, Viola R, Pertot I, Cavalieri D, Blaxter M, Anfora G, RotaStabelli O (2013) Linking genomics and ecology to investigate the complex evolution of an invasive Drosophila pest. Genome Biol Evol 5:745-757. https://doi.org/10.1093/gbe/evt034

Orhan A, Aslantaş R, Önder BŞ, Tozlu G (2016) First record of the invasive vinegar fly Drosophila suzukii (Matsumura) (Diptera: Drosophilidae) from eastern Turkey. Turk J Zool 40:290-293. https://doi.org/10.3906/zoo-1412-25

Pereira R, Yuval B, Liedo P, Teal PEA, Shelly TE, McInnis DO, Hendrichs J (2013) Improving sterile male performance in support of programmes integrating the sterile insect technique against fruit flies. J Appl Entomol 137:178-190. https://doi. org/10.1111/j.1439-0418.2011.01664.x

Pimentel D, Lach L, Zuniga R, Morrison D (2000) Environmental and economic costs of non-indigenous species in the United States. Bioscience 50:53-65. https://doi. org/10.1641/0006-3568(2000)050[0053:EAECON]2.3.CO;2

Pimentel D, Zuniga R, Morrison D (2005) Update on the environmental and economic costs associated with alien-invasive species in the United States. Ecol Econ 52:273-288

Plantamp C, Salort K, Gibert P, Dumet A, Mialdea G, Mondy N, Voituron Y (2016) All or nothing: survival, reproduction and oxidative balance in spotted wing Drosophila (Drosophila suzukii) in response to cold. J Insect Physiol 89:28-36. https://doi. org/10.1016/j.jinsphys.2016.03.009

Poyet M, Havard S, Prevost G, Chabrerie O, Doury G, Gibert P, Eslin P (2013) Resistance of Drosophila suzukii to the larval parasitoids Leptopilina heterotoma and Asobara japonica is related to haemocyte load. Physiol Entomol 38:45-53. https://doi. org/10.1111/phen.12002

Poyet M, Eslin P, Héraude M, Le Roux V, Prévost G, Gibert G, Gibert $P$ (2014) Invasive host for invasive pest: when the Asiatic cherry fly (Drosophila suzukii) meets the American black cherry (Prunusserotina) in Europe. Agric For Entomol 16:251-259. https:// doi.org/10.1111/afe.12052

Poyet M, Le Roux V, Gibert P, Meirland A, Prevost G, Eslin P, Chabrerie $\mathrm{O}(2015)$ The wide potential trophic niche of theAsiatic fruit fly Drosophila suzukii: the key of its invasive success in temperate Europe? PLoS ONE 10:e0142785. https://doi.org/10.1371/ journal.pone.0142785

Raphael KA, Shearman DCA, Gilchrist AS, Sved JA, Morrow JL, Sherwin WB, Riegler M, Frommer M (2014) Australian endemic pest tephritids: genetic, molecular and microbial tools for improved sterile insect technique. BMC Genet 15(Suppl 2):S9

Rendon P, McInnis D, Lance D, Stewart J (2000) Comparison of Medfly male-only and bisexual releases in large scale field trials. In: Area-wide control of fruit flies and other insect pests. Joint proceedings of the international conference on area-wide control of insect pests, 28 May-2 June, 1998 and the fifth international symposium on fruit flies of economic importance, Penang, Malaysia, 1-5 June, 1998 2000, pp 517-525

Rogers MA, Burkness EC, Hutchison WD (2016) Evaluation of high tunnels for management of Drosophila suzukii in fall-bearing red raspberries: potential for reducing insecticide use. J Pest Sci 89:815-821. https://doi.org/10.1007/s10340-016-0731-1

Rossi Stacconi MV, Buffington M, Daane KM, Dalton DT, Grassi A et al (2015) Host stage preference, efficacy and fecundity of parasitoids attacking Drosophila suzukii in newly invaded areas. Biol Control 84:28-35. https://doi.org/10.1016/j. biocontrol.2015.02.003

Rossi-Stacconi MV, Grassi A, Dalton DT, Miller B, Ouantar M, Loni A, Ioriatti C, Walton VM, Anfora G (2013) First field records of Pachycrepoideus vindemiae as a parasitoid of Drosophila suzukii in European and Oregon small fruit production areas. Entomologia 1:e3

Rossi-Stacconi MV, Kaur R, Mazzoni V et al (2016) Multiple lines of evidence for reproductive winter diapause in the invasive pest Drosophila suzukii: useful clues for control strategies. J Pest Sci 89:689. https://doi.org/10.1007/s10340-016-0753-8

Rota-Stabelli O, Blaxter M, Anfora G (2013) Drosophila suzukii. Curr Biol 23:R8-R9. https://doi.org/10.1016/j.cub.2012.11.021

Ryan GD, Emiljanowicz L, Wilkinson F, Kornya M, Newman JA (2016) Thermal tolerances of the spotted-wing drosophila Drosophila suzukii. J Econ Entomol 109:746-752

Saridaki A, Bourtzis K (2010) Wolbachia: more than just a bug in insects genitals. Curr Opin Microbiol 13:67-72. https://doi. org/10.1016/j.mib.2009.11.005 
Servicio Agrícola y Ganadero (SAG) (2017). Resolución exenta No: 3672/2017: Establece medidas fitosanitarias de emergencia provisionales para la plaga drosófila de alas Manchadas, Drosophila suzukii (Matsumura). Diptera: Drosophilidae. http://www.sag. gob.cl/sites/default/files/res_3672_13jun2017.pdf. Accessed 22 Aug 2017

Sharon G, Segal D, Ringo JM, Hefetz A, Zilber-Rosenberg I, Rosenberg E (2010) Commensal bacteria play a role in mating preference of Drosophila melanogaster. PNAS 107:20051-20056. https://doi.org/10.1073/pnas.1009906107

Shearer PW, West JD, Walton VM, Brown PH, Svetec N, Chiu JC (2016) Seasonal cues induce phenotypic plasticity of Drosophila suzukii to enhance winter survival. BMC Ecol 16:11. https://doi. org/10.1186/s12898-016-0070-3

Siozios S, Cestaro A, Kaur R, Pertot I, Rota-Stabelli O, Anfora G (2013) Draft genome sequence of the Wolbachia endosymbiont of Drosophila suzukii. Genome Announc 1:e00032. https://doi. org/10.1128/genomeA.00032-13

Staubach F, Baines JF, Künzel S, Bik EM, Petrov DA (2013) Host species and environmental effects on bacterial communities associated with Drosophila in the laboratory and in the natural environment. PLoS ONE 8:e70749. https://doi.org/10.1371/ journal.pone.0070749

Stephens AR, Asplen MK, Hutchison WD, Venette RC (2015) Cold hardiness of winter-acclimated Drosophila suzukii (Diptera: Drosophilidae) adults. Environ Entomol 44:1619-1626. https:// doi.org/10.1093/ee/nvv134

Teixeira L, Ferreira A, Ashburner M (2008) The bacterial symbiont Wolbachia induces resistance to RNA viral infections in Drosophila melanogaster. PLoS Biol 6:e2. https://doi.org/10.1371/ journal.pbio.1000002

Tochen S, Dalton DT, Wiman N, Hamm C, Shearer PW, Walton VM (2014) Temperature-related development and population parameters for Drosophila suzukii (Diptera: Drosophilidae) on cherry and blueberry. Environ Entomol 43:501-510. https://doi. org/10.1603/EN13200

Toxopeus J, Jakobs R, Ferguson LV, Gariepy TD, Sinclair BJ (2016) Reproductive arrest and stress resistance in winter-acclimated Drosophila suzukii. J Insect Physiol 89:37-51. https://doi. org/10.1016/j.jinsphys.2016.03.006

Vilela CR, Mori L (2014) The invasive spotted-wing Drosophila (Diptera, Drosophilidae) has been found in the city of São Paulo (Brazil). Revista Brasileira de Entomologia 58:371-375

Vreysen MJB, Hendrichs J, Enkerlin WR (2006) The sterile insect technique as a component of sustainable area-wide integrated pest management of selected horticultural insect pests. Research Institute of Pomology and Floriculture in Journal of Fruit and Ornamental Plant Research 14; 107-132; Pest and weed control in sustainable fruit production by Research Institute of Pomology and Floriculture

Vreysen MJB, Saleh K, Mramba F, Parker A, Feldmann U, Dyck VA (2014) Sterile insects to enhance agricultural development: the case of sustainable tsetse eradication on Unguja Island, Zanzibar, using an area-wide integrated pest management approach. PLoS Negl Trop Dis 8:e2857. https://doi.org/10.1371/journal. pntd.0002857

Wallingford AK, Loeb GM (2016) Developmental acclimation of Drosophila suzukii (Diptera: Drosophilidae) and its effect on diapause and winter stress tolerance. Environ Entomol 45:1081-1089. https://doi.org/10.1093/ee/nvw088

Wallingford AK, Lee JC, Loeb GM (2016) The influence of temperature and photoperiod on the reproductive diapause and cold tolerance of spotted-wing drosophila, Drosophila suzukii. Entomol Exp Appl 159:327-337. https://doi.org/10.1111/eea.12443

Walsh DB, Bolda MP, Goodhue RE, Dreves AJ, Lee J, Bruck DJ, Walton VM, O'Neal SD, Zalom FG (2011) Drosophila suzukii
(Diptera: Drosophilidae): invasive pest of ripening soft fruit expanding its geographic range and damage potential. J Integr Pest Manag 2:G1-G7. https://doi.org/10.1603/IPM10010

Wang XG, Kaçar G, Biondi A, Daane KM (2016) Foraging efficiency and outcomes of interactions of two pupal parasitoids attacking the invasive spotted wing Drosophila. Biol Control 96:64-71

Weiss B, Aksoy S (2011) Microbiome influences on insect host vector competence. Trends Parasitol 27:514-522. https://doi. org/10.1016/j.pt.2011.05.001

Werren JH (1997) Biology of Wolbachia. Annu Rev Entomol 42:587-609

Werren JH, Baldo L, Clark ME (2008) Wolbachia: master manipulators of invertebrate biology. Nat Rev Microbiol 6:741-751. https:// doi.org/10.1038/nrmicro1969

Woltz JM, Donahue KM, Bruck DJ, Lee JC (2015) Efficacy of commercially available predators, nematodes and fungal entomopathogens for augmentative control of Drosophila suzukii. J Appl Entomol 139:759-770

Wong AC, Chaston JM, Douglas AE (2013) The inconstant gut microbiota of Drosophila species revealed by $16 \mathrm{~S}$ rRNA gene analysis. ISME J 7:1922-1932. https://doi.org/10.1038/ismej.2013.86

Yun JH, Roh SW, Whon TW, Jung MJ, Kim MS, Park DS, Yoon C, Nam YD, Kim YJ, Choi JH, Kim JY, Shin NR, Kim SH, Lee WJ, Bae JW (2014) Insect gut bacterial diversity determined by environmental habitat, diet, developmental stage, and phylogeny of host. Appl Environ Microbiol 80:5254-5264. https://doi. org/10.1128/AEM.01226-14

Zabalou S, Riegler M, Theodorakopoulou M, Stauffer C, Savakis C, Bourtzis K (2004) Wolbachia-induced cytoplasmic incompatibility as a means for insect pest population control. Proc Natl Acad Sci USA 101:15042-15045

Zabalou S, Apostolaki A, Pattas S, Veneti Z, Paraskevopoulos C, Livadaras I, Markakis G, Brissac T, Merçot H, Bourtzis K (2008) Multiple rescue factors within a Wolbachia strain. Genetics 178:2145-2160. https://doi.org/10.1534/genetics.107.086488

Zabalou S, Apostolaki A, Livadaras I, Franz G, Robinson A, Savakis C, Bourtzis K (2009) Incompatible insect technique: incompatible males from a Ceratitis capitata genetic sexing strain. Entomol Exp Appl 132:232-240. https://doi. org/10.1111/j.1570-7458.2009.00886.x

Zchori-Fein E, Bourtzis K (2011) Manipulative tenants-bacteria associated with arthropods. CRC Press, Boca Raton

Zerulla FN, Schmidt S, Streitberger M, Zebitz CPW, Zelger R (2015) On the overwintering ability of Drosophila suzukii in South Tyrol. J Berry Res 5:41-48. https://doi.org/10.3233/JBR-150089

Zhai Y, Lin Q, Zhang J, Zhang F, Zheng L, Yu Y (2016) Adult reproductive diapause in Drosophila suzukii females. J Pest Sci 89:679-688

Zhang D, Lees RS, Xi Z, Gilles JR, Bourtzis K (2015a) Combining the sterile insect technique with Wolbachia-based approaches: II-a safer approach to Aedes albopictus population suppression programmes, designed to minimize the consequences of inadvertent female release. PLoS ONE 10:e0135194. https://doi.org/10.1371/ journal.pone. 0135194

Zhang D, Zheng X, Xi Z, Bourtzis K, Gilles JR (2015b) Combining the sterile insect technique with the incompatible insect technique: I-impact of Wolbachia infection on the fitness of tripleand double-infected strains of Aedes albopictus. PLoS ONE 10:e0121126. https://doi.org/10.1371/journal.pone.0121126

Zhang D, Lees RS, Xi Z, Bourtzis K, Gilles JR (2016) Combining the sterile insect technique with the incompatible insect technique: III- Robust mating competitiveness of irradiated triple Wolbachia-infected Aedes albopictus males under semi-field conditions. PLoS ONE 11:e0151864 
Zindel R, Gottlieb Y, Aebi A (2011) Arthropod symbioses: a neglected parameter in pest- and disease-control programmes. J Appl Ecol 48:864-872. https://doi.org/10.1111/j.1365-2664.2011.01984.x

Zug R, Hammerstein P (2015) Bad guys turned nice? A critical assessment of Wolbachia mutualisms in arthropod hosts. Biol Rev 90:89-111
Zygouridis NE, Argov Y, Nemny-Lavy E, Augustinos AA, Nestel D, Mathiopoulos KD (2014) Genetic changes during laboratory domestication of an olive fly SIT strain. J Appl Entomol 138:423-432. https://doi.org/10.1111/jen. 12042 